\title{
Potencial fisiológico de sementes armazenadas e desempenho de plantas de ervilha ${ }^{1}$
}

\author{
Fábio Mielezrski², Júlio Marcos Filho ${ }^{2}$
}

\begin{abstract}
RESUMO-Os efeitos do vigor de lotes de sementes sobre a emergência das plântulas e estabelecimento do estande, principalmente sob condições menos favoráveis de ambiente, estão bem documentados na literatura. Porém, há necessidade de intensificar a pesquisa para esclarecer as relações entre o potencial fisiológico das sementes e o desempenho das plantas em campo; este foi o principal objetivo deste estudo.Utilizaram-se duas cultivares de ervilha, 'Telefone Alta' (crescimento indeterminado) e 'Itapuã' (determinado), cada uma representada por quatro lotes armazenados, durante oito meses, em três ambientes: laboratório, câmara fria e seca $\left(10^{\circ} \mathrm{C}\right.$ e $30 \%$ de umidade relativa do ar) e ambiente controlado $\left(20^{\circ} \mathrm{C}\right.$ e $70 \%$ de umidade relativa do ar); este procedimento permitiu criar diferenças entre o potencial fisiológico dos lotes de cada cultivar. Após a determinação da germinação e do vigor (condutividade elétrica, envelhecimento acelerado, comprimento e emergência de plântulas), foi conduzido ensaio de campo, realizando-se avaliações do estande inicial e final, altura e área foliar de plantas, número de vagens e produção de grãos verdes e secos. $\mathrm{O}$ vigor das sementes de ervilha influencia a emergência de plântulas e o estabelecimento do estande em campo, especialmente em lotes pouco vigorosos. O vigor de sementes de ervilha afeta negativamente o desenvolvimento das plantas e a produção final, quando há redução acentuada do estande; a extensão desses efeitos é proporcional à intensidade dessa redução.
\end{abstract}

Termos para indexação: Pisum sativum, vigor de sementes, armazenamento, deterioração, produção de grãos.

\section{Physiological quality of stored pea seeds and plant performance}

ABSTRACT - The effects of seed vigor on seedling emergence and stand establishment, especially under less favorable environmental conditions, are well documented in the literature. However, additional research is needed to clarify the relationships between seed physiological quality and field plant performance, and this was the main objective of this study. Two pea cultivars, 'Telefone Alta' (indeterminate growth habit) and 'Itapuã' (determinate growth habit) were evaluated, each represented by four seed lots of different physiological potential, stored for eight months under three environmental conditions: uncontrolled laboratory, a dry and cold chamber at $10{ }^{\circ} \mathrm{C}$ and $30 \%$ relative humidity, and a controlled environment $\left(20^{\circ} \mathrm{C}\right.$ and $70 \%$ relative humidity); this procedure was adopted to promote natural differences in vigor among the seed lots. After determining germination and vigor (electrical conductivity, accelerated aging, seedling emergence and growth), a field trial was conducted to evaluate stand establishment, plant development and yield. Results showed that pea seed vigor influenced seedling emergence and stand establishment, especially for lower vigor seed lots. In addition, pea seed vigor adversely affected plant development and yield as a consequence of stand reduction. The extent of these effects was proportional to the intensity of the stand reduction.

Index terms: Pisum sativum, seed vigor, storage, deterioration, yield.

\footnotetext{
Submetido em 30/01/2012. Aceito para publicação em 20/07/2012.

${ }^{2}$ Departamento de Produção Vegetal, USP/ESALQ, Caixa Postal 9, 13418-900 - Piracicaba, SP, Brasil.

*Autor para correspondência <juliomarcos.1@usp.br>
} 


\section{Introdução}

A ervilha (Pisum sativum, L.) é amplamente cultivada para o consumo humano, pois é rica de proteínas e carboidratos, cálcio, fósforo e vitaminas A e C. Em cultivares utilizadas na forma de grãos secos, pode ser obtida a farinha de ervilha, com emprego direto na fabricação de sopas instantâneas e na panificação. $\mathrm{Na}$ forma de grãos verdes debulhados, a ervilha pode ser comercializada para consumo in natura, enlatada ou congelada imediatamente após a colheita (Giordano, 1997; Nascimento et al., 2007).

As cultivares destinadas à produção de grãos verdes debulhados para consumo in natura possuem sementes com predomínio do teor de açúcar em relação ao de amido e são rugosas após a secagem, enquanto em cultivares de sementes lisas, o teor de amido supera o de açúcares. Essas características estão associadas ao potencial fisiológico, sendo as rugosas mais problemáticas quanto ao desempenho após a semeadura, potencial de armazenamento e sanidade (Nascimento e Cícero, 1991a, b).

Os efeitos do vigor de lotes de sementes sobre a emergência das plântulas, estabelecimento do estande e desenvolvimento inicial das plantas, principalmente sob condições menos favoráveis de ambiente, estão bem documentados na literatura. No entanto, não está completamente esclarecido até que ponto esses efeitos se estendem até estádios fenológicos mais avançados e afetam a produção da cultura. Os resultados de germinação obtidos em laboratório geralmente se aproximam da porcentagem de emergência de plântulas em campo, sob condições ambientais adequadas após a semeadura, mas isto geralmente não se verifica quando essas condições se desviam das mais favoráveis.

A influência do vigor de sementes sobre o desempenho inicial das plântulas foi destacada, dentre outros, por Edje e Burris (1971) com soja, Khah et al. (1989) com trigo, Schuch et al. (1999) com aveia preta, Kolchinski et al. (2006) com soja, indicando que sementes menos vigorosas emergiram mais lentamente e produziram plantas com menor desenvolvimento inicial, manifestado pela redução da área foliar ou produção de massa seca. Essas observações também foram efetuadas em pesquisas com hortaliças (Rodo e Marcos Filho, 2003, com cebola; Marcos Filho e Kikuti, 2006, com rabanete; Kikuti e Marcos Filho, 2007, com couve-flor), mas as relações entre o vigor das sementes e o desempenho das plantas observadas durante a fase inicial do desenvolvimento da cultura, não persistiram até o final do ciclo. Por outro lado, Mondo (2009), trabalhando com sementes de milho, constatou que as plantas originadas de sementes de baixo vigor apresentaram crescimento inicial inferior, contribuindo para a desuniformidade da população e resultando em menor capacidade competitiva dessas plantas.

Quando se consideram estudos para estabelecer relações do vigor com o desenvolvimento das plantas e produção, a literatura é relativamente escassa. Há necessidade de considerar dois aspectos: a ocorrência ou não de diferenças no estande e a identificação de possíveis efeitos do vigor dos lotes de sementes sobre o desempenho, quando se consideram plantas individuais ou populações.

Larsen et al. (1998) destacaram que a influência do vigor de sementes pode persistir durante todo o desenvolvimento das plantas, mesmo quando não há diferenças no estande inicial, embora essas diferenças possam se atenuar com o decorrer dos estádios fenológicos. Em contraste, Hampton (2002) enfatizou que efeitos do vigor na produção final das plantas só aparecem se houver diferenças no estabelecimento do estande. Essa diversidade de opiniões é verificada, com frequência, ao se examinar a literatura sobre o assunto.

Pesquisas têm sido conduzidas visando esclarecer até que ponto os efeitos do vigor independem da população inicial. Zecchinelli (2009) destacou que a redução da germinação e do vigor afeta negativamente o estabelecimento do estande e isto pode causar diferenças no desenvolvimento das plantas e na produção da cultura, principalmente em espécies em que o produto comercial é obtido de plantas individualizadas, como várias hortaliças. Paralelamente, culturas de gramíneas semeadas sob espaçamentos relativamente estreitos, como arroz, trigo e cevada, podem perfilhar e compensar, dentro de limites, a possível redução na emergência de plântulas, de modo que a produção por área seria mantida, mesmo com variações mais acentuadas da população. O mesmo ocorreria em várias leguminosas, em que a produção por planta é ajustada mediante a adaptação ao espaço disponível, isto é, maior produção individual de plantas sob menor competição; essa compensação, refletindo a plasticidade das plantas, dependeria, ainda, do hábito de crescimento da cultivar, sendo as de crescimento indeterminado mais eficientes na ocupação do espaço disponível.

Consequentemente, tanto a germinação como o vigor parecem ser mais importantes para o estabelecimento do estande em espécies com capacidade mais restrita de compensar falhas no estande, como milho, algodão, girassol e várias hortaliças (alface, cenoura, repolho e outras). Ellis (1992) ressaltou que os efeitos do vigor sobre a porcentagem e velocidade de 
emergência de plântulas podem interferir na população de plantas por área, em seu arranjo espacial e, indiretamente, na produção final, mas os efeitos diretos do vigor da semente no desempenho das plantas e na produção são muito difíceis de serem identificados.

Há consenso, na literatura, quanto à superioridade da produção de plantas individuais originadas de sementes mais vigorosas (Melo et al., 2006; Mielezrski et al., 2008; Mondo, 2009; Schuch et al., 2009), mas estudos envolvendo populações têm proporcionado conclusões menos consistentes sobre os efeitos positivos do vigor (Vanzolini e Carvalho, 2002), a não ser em populações homogêneas, constituídas apenas por sementes de alto ou de baixo vigor (Schuch et al., 2009; Scheeren et al., 2010).

De qualquer maneira, somente a influência do vigor sobre o estabelecimento do estande já seria suficiente para justificar o uso de sementes de alto potencial fisiológico. TeKrony e Egli (1991) enfatizaram que a produção de grãos não é totalmente dependente do grau de desenvolvimento vegetativo, desde que este tenha ultrapassado um determinado nível mínimo, de modo que apenas variações acentuadas entre o vigor de lotes de sementes poderiam provocar diferenças na produção final.

Diante do exposto, considerando-se a importância econômica da cultura da ervilha e a escassez de informações na literatura, principalmente as relacionadas ao comportamento de cultivares com sementes rugosas, esta pesquisa visou, principalmente, verificar a extensão de relações entre o potencial fisiológico, estabelecimento do estande e desenvolvimento de plantas de ervilha, comparando cultivares de hábito de crescimento determinado e indeterminado que produzem sementes rugosas destinadas ao consumo de grãos verdes debulhados.

\section{Material e Métodos}

O estudo foi conduzido com utilização de duas cultivares de ervilha, Telefone Alta (Alderman) e Itapuã 600, ambas de sementes rugosas, produzidas por ISLA Sementes Ltda.e representadas por quatro lotes. As sementes eram tratadas com Thiram (200 g i.a./ $100 \mathrm{~kg}$ de sementes).

A cultivar Itapuã 600, de hábito de crescimento determinado, apresenta ciclo médio de 60-70 dias, altura média de plantas de 40-50 cm, tipo de vagem reta/cilíndrica, comprimento médio da vagem de $9-11 \mathrm{~cm}$. A cultivar Telefone Alta (Alderman), de hábito indeterminado, tem ciclo médio de 90-110 dias, altura média de plantas de 90$110 \mathrm{~cm}$, tipo de vagem curva/cilíndrica, comprimento médio da vagem de $10-12 \mathrm{~cm}$, tolerância à temperatura mínima do solo de $4{ }^{\circ} \mathrm{C}$ e máxima de $29{ }^{\circ} \mathrm{C}$ (informações fornecidas por ISLA Sementes). Essas cultivares são recomendadas para semeadura de abril a agosto, no estado de São Paulo, produzem sementes rugosas e são comercializadas na forma de grãos verdes para debulha e consumo in natura.

Os lotes apresentavam germinação superior à mínima estabelecida para comercialização de sementes de ervilha (80\%) e diferenças quanto ao vigor. Após a recepção, foram colocados em sacas de tela de algodão e armazenados em ambientes distintos durante oito meses (dezembro 2008 a agosto de 2009): a) ambiente de laboratório, com registro diário da temperatura e da umidade relativa do ar (AL); b) câmara fria e seca, a $10^{\circ} \mathrm{C}$ e $30 \%$ de umidade relativa do ar (CFS); c) ambiente controlado, a $20{ }^{\circ} \mathrm{C}$ e $70 \%$ de umidade relativa do ar (AC), em caixas de plástico com o uso de solução de $\mathrm{NaCl}$, em concentração adequada para manter esse ambiente com umidade relativa do ar próxima de $70 \%$ (Sun, 2002).

$\mathrm{O}$ armazenamento nesses três ambientes teve como objetivo a obtenção de materiais com diferentes níveis de deterioração e, consequentemente, com variações suficientes no potencial fisiológico. A caracterização dessas amostras, após oito meses de armazenamento, envolveu avaliações do teor de água e do potencial fisiológico das sementes, mediante os seguintes testes:

Teor de água: determinado pelo método da estufa a $105 \pm 3{ }^{\circ} \mathrm{C}$ durante 24 horas, conforme as Regras para Análise de Sementes - RAS (Brasil, 2009).

Germinação: quatro repetições de 50 sementes foram distribuídas em rolos de papel toalha umedecidos com quantidade de água equivalente a 2,5 vezes o peso do substrato, a $20{ }^{\circ} \mathrm{C}$, conforme as Regras para Análise de Sementes (Brasil, 2009).

Condutividade elétrica: conduzido com quatro repetições de 25 sementes previamente pesadas $(0,01 \mathrm{~g})$, colocadas em copos de plástico com $75 \mathrm{~mL}$ de água destilada e mantidas em germinador a $20^{\circ} \mathrm{C}$, durante $24 \mathrm{~h}$. A condutividade foi determinada em condutivímetro digital e, os resultados, expressos em $\mu$ mho $\mathrm{cm}^{-1} \mathrm{~g}^{-1}$ de sementes (Vieira e Krzyzanowski, 1999), para cada lote e cultivar.

Envelhecimento acelerado: conduzido a $41{ }^{\circ} \mathrm{C}$ durante 48 h, em câmara apropriada, conforme Caliari e Marcos Filho (1990). Registraram-se as porcentagens de plântulas normais aos cinco dias após a semeadura, para cada lote e cultivar.

Comprimento de plântulas: utilizaram-se quatro repetições de 20 sementes por lote. Os rolos de papel toalha foram umedecidos com quantidade de água equivalente a 
2,5 vezes o peso do substrato e mantidos em germinador a $20{ }^{\circ} \mathrm{C}$, durante cinco dias; o comprimento de plântulas normais foi mensurado em centímetros, com auxílio de régua graduada (Nakagawa, 1999).

Emergência de plântulas: determinada com quatro repetições de 100 sementes por lote, com distribuição de 25 sementes $/ \mathrm{m}$ linear, a $5 \mathrm{~cm}$ de profundidade, seguindo espaçamento de $0,50 \mathrm{~m}$ entre sulcos. As contagens foram efetuadas aos 15 dias após a semeadura, determinando-se o número de plântulas emersas (Caliari e Marcos Filho, 1990). Os resultados foram expressos em porcentagem média de plântulas normais para cada lote e cultivar.

Avaliação do desenvolvimento e produção das plantas em campo: o preparo do solo foi efetuado pelo sistema convencional; em seguida, efetuou-se a correção da fertilidade do solo, classificado como Terra roxa estruturada eutrófica, com base em indicações técnicas para a cultura da ervilha (Giordano, 1997). A adubação constou da aplicação de 16 kg.ha- ${ }^{-1}$ de N, 90 kg.ha- ${ }^{-1}$ de P e 70 kg.ha- ${ }^{-1}$ de $\mathrm{K}$, utilizando adubo NPK, fórmula 8-16-26, no momento da semeadura. $O$ terreno utilizado era homogêneo, não apresentando manchas de fertilidade.
A semeadura foi realizada manualmente em agosto de 2009 , obedecendo ao espaçamento de $0,50 \mathrm{~cm}$ entre linhas; a profundidade de semeadura foi de $5 \mathrm{~cm}$. A quantidade de sementes utilizadas para cada parcela foi calculada com base nos valores obtidos no teste de germinação de cada lote e ambiente de armazenamento, procurando-se obter estande uniforme de 9 plantas. $\mathrm{m}^{-1}$ linear e uma população aproximada de 180.000 plantas.ha $^{-1}$ (Wutke et al., 1991).

$\mathrm{O}$ ensaio de campo foi instalado de acordo com delineamento blocos ao acaso, com quatro repetições, totalizando 16 parcelas (4 lotes $\mathrm{x} 3$ ambientes) por bloco, para cada cultivar. Cada parcela foi constituída por seis linhas com $5 \mathrm{~m}$ de comprimento; as duas linhas laterais de cada parcela e $0,5 \mathrm{~m}$ de cada extremidade das 4 linhas centrais constituíram as bordaduras, de modo que a área útil de cada parcela foi de $8 \mathrm{~m}^{2}$. Ao longo do ciclo das plantas foram realizados todos os tratos culturais destinados ao desenvolvimento adequado, inclusive o tratamento fitossanitário e irrigação, quando necessários.

As médias mensais de precipitação pluvial e temperatura durante o período de condução dos experimentos são apresentadas na Tabela 1 .

Tabela 1. Médias mensais de precipitação pluvial $(\mathrm{mm})$, temperaturas máxima, mínima e média $\left({ }^{\circ} \mathrm{C}\right)$ do ambiente, no período referente ao experimento de campo (agosto/2009 a dezembro/2009).

\begin{tabular}{lcccc}
\hline \multicolumn{1}{c}{ Mês/Ano } & $\begin{array}{c}\text { Precipitação } \\
\text { pluvial }(\mathrm{mm})\end{array}$ & $\begin{array}{c}\text { Temperatura } \\
\text { máxima }\left({ }^{\circ} \mathrm{C}\right)\end{array}$ & $\begin{array}{c}\text { Temperatura } \\
\text { Mínima }\left({ }^{\circ} \mathrm{C}\right)\end{array}$ & $\begin{array}{c}\text { Temperatura } \\
\text { Média }\left({ }^{\circ} \mathrm{C}\right)\end{array}$ \\
\hline Agosto/2009 & 61,4 & 26,3 & 13,2 & 19,7 \\
Setembro/2009 & 143,8 & 27,6 & 16,8 & 22,2 \\
Outubro/2009 & 56,7 & 29,1 & 15,8 & 22,4 \\
Novembro/2009 & 196,5 & 29,6 & 16,8 & 23,2 \\
Dezembro/2009 & 263,5 & 29,3 & 19,6 & 23,7 \\
\hline
\end{tabular}

Avaliação do desenvolvimento vegetativo: foram efetuadas avaliações do desenvolvimento vegetativo, a partir do estádio II (fase de emergência de plântulas) até o início do estádio IV (início do florescimento), ou seja, aos 15, 29 e 43 dias após a semeadura, conforme Makasheva (1984); foram considerados para análise estatística os dados das determinações efetuadas aos 15 e aos 43 dias. Coletaram-se amostras de seis plantas por tratamento, em cada parcela, totalizando dezoito plantas por tratamento, nessas três épocas; essas coletas foram efetuadas aleatoriamente em cada parcela, procurandose obter plantas competitivas e que representassem o grau de desenvolvimento predominante em cada parcela, sem deixar espaços vazios que pudessem comprometer a consistência das futuras determinações. Foram realizadas as seguintes avaliações:

Emergência de plântulas: determinada na área útil de cada parcela, realizando-se as contagens conforme o procedimento descrito anteriormente. Os resultados foram expressos em porcentagem média de emergência de plântulas e número de plântulas por metro linear.

Altura de plantas: foi determinada em cm, entre o colo da planta e o meristema apical, obtendo-se valor médio por parcela.

Massa da matéria seca: as plantas utilizadas para avaliação da altura foram cortadas rente ao solo, colocadas em sacos de papel e levadas a estufa com circulação forçada de ar, a $65^{\circ} \mathrm{C}$, durante $72 \mathrm{~h}$. Cada repetição foi pesada com precisão de 0,001 g (Nakagawa, 1999); também foram utilizadas as mesmas plantas avaliadas quanto à altura.

Área foliar: avaliada em determinador de área foliar 
(modelo LI-COR LI3100), sendo os valores expressos em $\mathrm{cm}^{2}$ planta $^{-1}$, utilizando-se as mesmas plantas avaliadas quanto à altura.

Produção: a colheita dos grãos foi realizada em dois momentos, simulando a obtenção de produtos para a comercialização como grãos debulhados (verdes) e como sementes (secos):

a) Grãos verdes: ponto de colheita dos grãos verdes com grau de umidade próximo de 50\% (ISLA Sementes, comunicação pessoal). A colheita foi realizada aos 75 dias após a semeadura, para 'Telefone Alta', e aos 55 dias após a semeadura para 'Itapuã 600 '. Nessa época, as vagens e grãos encontravam-se tenros, com coloração verde e, as plantas, em início de senescência.

b) Grãos secos: colhidos com grau de umidade aproximado de 14\% (Giordano, 1997). A colheita foi realizada próximo aos 90 dias após a semeadura, para 'Telefone Alta'(hábito indeterminado) e aos 70 dias após a semeadura, para 'Itapuã 600'(determinado). As plantas estavam em fase de senescência, com as vagens secas.

Como cada parcela era constituída por seis linhas, as duas centrais foram colhidas para a determinação do peso de grãos secos e, a linha vizinha a cada uma destas, para avaliação da produção de grãos verdes. A colheita foi efetuada mediante o arranquio manual das plantas da área útil de cada parcela, seguindo-se a trilhagem manual e a pesagem dos grãos nos dois momentos de colheita. Foram realizadas as seguintes avaliações:

Estande final de plantas: efetuou-se a contagem do número de plantas da área útil da parcela. Os resultados foram expressos em número de plantas/m linear, para cada lote e cultivar.

Número de vagens por planta: expresso pela relação entre o número total de vagens e o número total de plantas coletadas.

Produção individual e rendimento de grãos: o resultado da produção individual foi expresso pela relação entre o peso total de grãos e o número total de plantas coletadas. Também foi calculada a produção média das plantas na parcela, em kg.ha- ${ }^{-1}$, para cada época de colheita; foi realizada correção do peso, com base nos graus de umidade de $50 \% \mathrm{e}$ $14 \%$, para os grãos verdes e secos, respectivamente.

Procedimento estatístico: os dados dos testes de laboratório foram analisados de acordo com delineamento fatorial, para avaliar efeitos de lotes e ambientes. Em campo, foi adotado delineamento blocos ao acaso, em arranjo fatorial (lotes $\mathrm{x}$ ambientes). As análises foram realizadas separadamente para cada cultivar e teste conduzido. As médias foram comparadas pelo teste de Tukey $(p \leq 0,05)$.

\section{Resultados e Discussão}

Há dois procedimentos básicos utilizados em estudos sobre avaliação da eficiência de testes de vigor ou verificação de efeitos do vigor sobre o desempenho de sementes e plantas em campo. No primeiro, são utilizados lotes com diferenças naturais de vigor, obtidos, por exemplo, de diferentes origens, estádios de maturação, de variações na metodologia de secagem ou armazenamento. No segundo, as variações de vigor entre lotes com potencial fisiológico semelhante são provocadas por envelhecimento artificial.

Neste trabalho, optou-se pela primeira alternativa. Os três ambientes de armazenamento apresentavam diferenças na umidade relativa e temperatura do ar, permitindo supor que essas variações poderiam afetar a velocidade e a intensidade de deterioração e, consequentemente, criar diferenças no vigor dos lotes de sementes das duas cultivares.

De fato, examinando-se a Tabela 2, referente a cultivar Telefone Alta, verifica-se que após oito meses de armazenamento, apenas o lote 4, quando mantido em laboratório (AL) e os lotes 1 e 4, em câmara fria e seca (CFS) possuíam germinação superior à estabelecida $(80 \%)$ para a comercialização de sementes de ervilha. Por outro lado, de um modo geral, as sementes de 'Itapuã 600' exibiram níveis menos intensos de deterioração, mas apenas os lotes 5 e 8 , nos três ambientes, superaram aquele mínimo e, em geral, apresentavam maior vigor que os demais.

Em estudos sobre o potencial fisiológico de lotes, principalmente quando o foco é dirigido a possíveis relações com o desempenho de sementes, é desejável a comparação entre materiais com germinação semelhante entre si e superior à exigida para comercialização. Os lotes apresentavam níveis distintos de deterioração após oito meses de armazenamento e, portanto, foram considerados aptos para atender os objetivos propostos.

Havia lotes com germinação relativamente elevada e diferenças quanto ao vigor, dependendo do ambiente considerado. Por exemplo, para 'Telefone Alta', o teste de condutividade elétrica acusou tendência para superioridade do potencial fisiológico do lote 4, em relação ao lote 1 , quando armazenados em câmara fria e seca (CFS) e em laboratório (AL), enquanto os lotes 5 e 8 de 'Itapuã 600' apresentaram comportamento distinto, dependendo do ambiente de armazenamento. Por outro lado, os lotes 2 e 3 de 'Telefone Alta' e os lotes 6 e 7 de 'Itapuã 600' possuíam, de um modo geral, germinação 
e vigor inferiores aos demais lotes dos respectivos cultivares. Desta maneira, com esses materiais foi possível verificar até que ponto as diferenças mais amplas e as mais estreitas entre os lotes poderiam se manifestar quanto ao estabelecimento do estande e desenvolvimento das plantas em campo.

Tabela 2. Cultivar Telefone Alta: germinação (G), envelhecimento acelerado (E.A.), condutividade elétrica (C.E.), comprimento de plântulas (C. Pl.) e emergência de plântulas (Emerg. Pl.) de quatro lotes de sementes após oito meses de armazenamento em laboratório (AL), câmara fria e seca (CFS) e ambiente controlado (AC).

\begin{tabular}{|c|c|c|c|c|}
\hline \multirow{2}{*}{ Testes } & \multirow{2}{*}{ Lotes } & \multicolumn{3}{|c|}{ Ambientes } \\
\hline & & $\mathrm{AL}$ & CFS & $\mathrm{AC}$ \\
\hline \multirow{5}{*}{$\mathrm{G}(\%)$} & 1 & $63 \mathrm{Bb}^{*}$ & $83 \mathrm{Aa}$ & $59 \mathrm{Ab}$ \\
\hline & 2 & $54 \mathrm{Ba}$ & $62 \mathrm{Ba}$ & $54 \mathrm{Aa}$ \\
\hline & 3 & $38 \mathrm{Cb}$ & $64 \mathrm{Ba}$ & $37 \mathrm{Bb}$ \\
\hline & 4 & $83 \mathrm{Aa}$ & $88 \mathrm{Aa}$ & $67 \mathrm{Ab}$ \\
\hline & CV (\%) & & 11,4 & \\
\hline \multirow{5}{*}{ EA. $(\%)$} & 1 & $08 \mathrm{ABb}$ & $11 \mathrm{Ba}$ & $02 \mathrm{Ab}$ \\
\hline & 2 & $01 \mathrm{Bb}$ & $17 \mathrm{Ba}$ & $05 \mathrm{Ab}$ \\
\hline & 3 & $02 \mathrm{Bb}$ & $16 \mathrm{Ba}$ & $01 \mathrm{Ab}$ \\
\hline & 4 & $25 \mathrm{Ab}$ & $33 \mathrm{Aa}$ & $04 \mathrm{Ac}$ \\
\hline & CV (\%) & & 29,1 & \\
\hline \multirow{5}{*}{$\begin{array}{c}\text { C.E. } \\
\left(\mu \mathrm{mho.cm}{ }^{-1} \cdot \mathrm{g}^{-1}\right)\end{array}$} & 1 & $170,4 \mathrm{ABb}$ & $154,5 \mathrm{ABa}$ & $181,6 \mathrm{Ab}$ \\
\hline & 2 & $216,8 \mathrm{Bc}$ & $192,0 \mathrm{ABa}$ & $202,0 \mathrm{ABb}$ \\
\hline & 3 & $235,4 \mathrm{Bb}$ & $206,6 \mathrm{Ba}$ & $257,3 \mathrm{Bb}$ \\
\hline & 4 & $151,9 \mathrm{Aab}$ & $138,3 \mathrm{Aa}$ & $181,1 \mathrm{Ab}$ \\
\hline & CV (\%) & & 8,1 & \\
\hline \multirow{5}{*}{ C.Pl. (cm.plântula ${ }^{-1}$ ) } & 1 & $9,5 \mathrm{Aa}$ & $9,8 \mathrm{Aa}$ & $10,1 \mathrm{Aa}$ \\
\hline & 2 & $5,9 \mathrm{Bc}$ & $10,3 \mathrm{Aa}$ & 7,3 BCb \\
\hline & 3 & $6,9 \mathrm{Bb}$ & $9,3 \mathrm{Ba}$ & $7,1 \mathrm{Cb}$ \\
\hline & 4 & $9,0 \mathrm{Ab}$ & $11,3 \mathrm{Aa}$ & $9,2 \mathrm{ABb}$ \\
\hline & CV (\%) & & 11,6 & \\
\hline \multirow{5}{*}{ Emerg.Pl. (\%) } & 1 & $36 \mathrm{Bb}$ & $65 \mathrm{Aa}$ & $27 \mathrm{Bb}$ \\
\hline & 2 & $25 \mathrm{Cb}$ & $48 \mathrm{Ba}$ & $34 \mathrm{Bab}$ \\
\hline & 3 & $26 \mathrm{BCb}$ & $43 \mathrm{Ba}$ & $21 \mathrm{Cb}$ \\
\hline & 4 & $54 \mathrm{Ab}$ & $75 \mathrm{Aa}$ & $38 \mathrm{Ac}$ \\
\hline & CV (\%) & & 15,5 & \\
\hline
\end{tabular}

Letras maiúsculas: comparações em cada coluna; letras minúsculas: comparações em cada linha (teste de Tukey, p $\leq 0,05$ ).

Aos oito meses de armazenamento, os testes de vigor identificaram a inferioridade do vigor dos lotes 2 e 3 e a superioridade dos lotes 1 e 4 de 'Telefone Alta' (Tabela 2). Para a cultivar Itapuã 600, evidenciou-se o maior potencial fisiológico dos lotes 5 e 8 , em relação aos lotes 6 e 7 (Tabela 3). Em ambas as cultivares, o decréscimo do vigor foi detectado por todos os testes conduzidos e foi menos intenso nas sementes armazenadas em câmara fria e seca. $\mathrm{Na}$ interpretação desses resultados, não foi incluída a referente ao envelhecimento acelerado, pois os efeitos foram muito drásticos e não permitiram a obtenção de informações utilizáveis.

A semeadura do ensaio de campo foi realizada na tentativa de obter populações semelhantes por parcela, mediante a correção da quantidade de sementes, com base na porcentagem de germinação de cada lote, prática recomendada pela pesquisa e usualmente adotada tanto pelos produtores de ervilha como de outras espécies produtoras de grãos.

Nesse ensaio, não foram constatadas diferenças na porcentagem de emergência de plântulas entre os lotes de 'Telefone Alta' armazenados em câmara fria e seca e em ambiente controlado, mas o lote 2, armazenado em laboratório originou média significativamente inferior aos demais (Tabela 4). Essas mesmas considerações se aplicam ao estande inicial (número de plantas por metro linear), de modo que foi possível estabelecer comparações entre os desempenhos de lotes, tanto 
na ausência (entre os lotes 1 e 4 de 'Telefone Alta' e entre os lotes 5 e 8 de 'Itapuã 600') como na presença de diferenças no estande inicial (entre os demais lotes, dentro de cada cultivar).

Tabela 3. Cultivar Itapuã: germinação (G), envelhecimento acelerado (E.A.), condutividade elétrica (C.E.), comprimento de plântulas (C. Pl.) e emergência de plântulas (Emerg. Pl.) de quatro lotes de sementes após oito meses de armazenamento em laboratório (AL), câmara fria e seca (CFS) e ambiente controlado (AC).

\begin{tabular}{|c|c|c|c|c|}
\hline \multirow{2}{*}{ Testes } & \multirow{2}{*}{ Lotes } & \multicolumn{3}{|c|}{ Ambientes } \\
\hline & & $\mathrm{AL}$ & CFS & $\mathrm{AC}$ \\
\hline \multirow{5}{*}{$\mathrm{G}(\%)$} & 5 & $86 \mathrm{Aa}^{*}$ & $94 \mathrm{Aa}$ & $88 \mathrm{Aa}$ \\
\hline & 6 & $70 \mathrm{Bab}$ & $81 \mathrm{Ba}$ & $55 \mathrm{Bb}$ \\
\hline & 7 & $39 \mathrm{Cb}$ & $60 \mathrm{Ca}$ & $31 \mathrm{Cb}$ \\
\hline & 8 & $91 \mathrm{Aa}$ & $95 \mathrm{Aa}$ & $93 \mathrm{Aa}$ \\
\hline & $\mathrm{CV}(\%)$ & & 10,4 & \\
\hline \multirow{5}{*}{ EA. $(\%)$} & 5 & $20 \mathrm{Bb}$ & $56 \mathrm{Ba}$ & $27 \mathrm{Ab}$ \\
\hline & 6 & $01 \mathrm{Cb}$ & $25 \mathrm{Ca}$ & $01 \mathrm{Bb}$ \\
\hline & 7 & $01 \mathrm{Cb}$ & $03 \mathrm{Da}$ & $01 \mathrm{Bb}$ \\
\hline & 8 & $47 \mathrm{Ab}$ & $79 \mathrm{Aa}$ & $24 \mathrm{Ac}$ \\
\hline & $\mathrm{CV}(\%)$ & & 22,4 & \\
\hline \multirow{5}{*}{$\begin{array}{c}\text { C.E. } \\
\left(\mu \mathrm{mho} . \mathrm{cm}^{-1} \cdot \mathrm{g}^{-1}\right)\end{array}$} & 5 & $115,1 \mathrm{Ba}$ & $111,0 \mathrm{Ba}$ & $133,5 \mathrm{Ba}$ \\
\hline & 6 & $138,3 \mathrm{Ba}$ & $133,7 \mathrm{Ba}$ & $162,3 \mathrm{Cb}$ \\
\hline & 7 & $187,6 \mathrm{Ca}$ & $194,2 \mathrm{Ca}$ & $207,9 \mathrm{Da}$ \\
\hline & 8 & $70,4 \mathrm{Aa}$ & $80,0 \mathrm{Aa}$ & $77,2 \mathrm{Aa}$ \\
\hline & $\mathrm{CV}(\%)$ & & 10,3 & \\
\hline \multirow{5}{*}{ C.Pl. (cm.plântula ${ }^{-1}$ ) } & 5 & $9,3 \mathrm{Ab}$ & $11,4 \mathrm{Ba}$ & $9,7 \mathrm{Ab}$ \\
\hline & 6 & $7,5 \mathrm{Bb}$ & $9,6 \mathrm{Ca}$ & $6,2 \mathrm{Bc}$ \\
\hline & 7 & $4,7 \mathrm{Cb}$ & $6,2 \mathrm{Da}$ & $3,9 \mathrm{Cb}$ \\
\hline & 8 & $10,2 \mathrm{Ab}$ & $12,8 \mathrm{Aa}$ & $10,2 \mathrm{Ab}$ \\
\hline & $\mathrm{CV}(\%)$ & & 8,3 & \\
\hline \multirow{5}{*}{ Emerg.Pl. (\%) } & 5 & $59 \mathrm{Bb}$ & $80 \mathrm{Aa}$ & $66 \mathrm{Bb}$ \\
\hline & 6 & $37 \mathrm{Cb}$ & $64 \mathrm{Ba}$ & $24 \mathrm{Cc}$ \\
\hline & 7 & $17 \mathrm{Db}$ & $31 \mathrm{Ca}$ & $19 \mathrm{Cb}$ \\
\hline & 8 & $85 \mathrm{Aa}$ & $90 \mathrm{Aa}$ & $87 \mathrm{Aa}$ \\
\hline & $\mathrm{CV}(\%)$ & & 9,3 & \\
\hline
\end{tabular}

Letras maiúsculas: comparações em cada coluna; letras minúsculas: comparações em cada linha (teste de Tukey, p $\leq 0,05$ ).

O estande de 9 plantas por metro linear, préestabelecido para as parcelas experimentais, não foi alcançado, mesmo efetuando-se a tentativa de "correção do estande", em lotes com potencial fisiológico inferior; as exceções foram verificadas para os lotes de 'Telefone Alta' armazenados em câmara fria e seca e os mais vigorosos de 'Itapuã 600'. Assim, apenas lotes com poder germinativo e vigor elevados foram capazes de alcançar a população recomendada, sob condições ambientais ligeiramente adversas em campo. Foram registradas temperaturas médias em torno de $20{ }^{\circ} \mathrm{C}$ durante e após a semeadura, enquanto a temperatura ótima para germinação de sementes de ervilha é de $18{ }^{\circ} \mathrm{C}$ (Kotowski, 1962); no entanto, houve vários dias com temperaturas inferiores à ótima, dificultando a emergência de plântulas. Abdalla e Roberts (1969), trabalhando com sementes de ervilha, verificaram, em lotes cuja germinação decresce para valores próximos a $60 \%$, que a distribuição de maior número de sementes para compensar possíveis falhas no estande, geralmente não é bem sucedida, devido ao grau avançado de deterioração desses lotes.

O exame da Tabela 5, para 'Telefone Alta', permite verificar a ausência de diferenças significativas entre lotes e ambientes, quanto à altura de plantas, massa de matéria seca e área foliar tanto aos 15 como aos 43 dias após a emergência de plântulas; no entanto, as plantas originadas de sementes do lote 3 armazenadas em câmara fria e seca foram exceções, apresentando menor área foliar aos 43 dias. Assim, esses resultados indicaram que as possíveis diferenças no vigor de sementes dessa cultivar não se manifestaram no desenvolvimento inicial das plantas, mesmo quando houve 
diferenças no estande inicial (comparações dos lotes 2 e 3 com os lotes 1 e 4 de 'Telefone Alta', por exemplo). Isto contraria as observações efetuadas por vários autores, como
Edje e Burris (1971), Schuch et al. (1999), Mondo (2009), dentre outros, segundo as quais as sementes de menor vigor dão origem a plantas menos desenvolvidas.

Tabela 4. Cultivar Telefone Alta: emergência de plântulas em campo, número inicial e final de plantas/m linear, número de vagens/planta, produção de sementes verdes/planta e rendimento de sementes verdes e secas (kgha $\left.{ }^{-1}\right)$ de plantas originadas de sementes armazenadas em laboratório (AL), câmara fria e seca (CFS) e ambiente controlado (AC).

\begin{tabular}{|c|c|c|c|c|}
\hline \multirow{2}{*}{ Parâmetros } & \multirow{2}{*}{ Lotes } & \multicolumn{3}{|c|}{ Ambientes } \\
\hline & & $\mathrm{AL}$ & CFS & $\mathrm{AC}$ \\
\hline \multirow{5}{*}{ Emergência Plântulas (\%) } & 1 & $70 \mathrm{Ab}^{*}$ & $94 \mathrm{Aa}$ & $63 \mathrm{Ab}$ \\
\hline & 2 & $48 \mathrm{Bb}$ & $100 \mathrm{Aa}$ & $64 \mathrm{Ab}$ \\
\hline & 3 & $75 \mathrm{Aa}$ & $84 \mathrm{Aa}$ & $70 \mathrm{Aa}$ \\
\hline & 4 & $84 \mathrm{Aab}$ & $98 \mathrm{Aa}$ & $77 \mathrm{Ab}$ \\
\hline & $\mathrm{CV}(\%)$ & & 11,5 & \\
\hline \multirow[t]{3}{*}{$\mathrm{N}^{\mathrm{o}}$ Inicial Plantas.m $\mathrm{m}^{-1}$} & 3 & $6,0 \mathrm{Aab}$ & $8,0 \mathrm{Aa}$ & $6,0 \mathrm{Aa}$ \\
\hline & 4 & $8,0 \mathrm{Aab}$ & $9,0 \mathrm{Aa}$ & $7,0 \mathrm{Ab}$ \\
\hline & CV (\%) & & 12,3 & \\
\hline \multirow{2}{*}{ № Final Plantas.m ${ }^{-1}$} & 1 & $5,0 \mathrm{ABb}$ & $8,0 \mathrm{Aa}$ & $5,0 \mathrm{Ab}$ \\
\hline & 2 & $4,0 \mathrm{Bc}$ & $9,0 \mathrm{Aa}$ & $5,0 \mathrm{Ab}$ \\
\hline \multirow{5}{*}{$\mathrm{N}^{\mathrm{o}}$ Vagens. Planta ${ }^{-1}$} & 1 & $3,5 \mathrm{Aa}$ & $3,7 \mathrm{ABa}$ & $4,7 \mathrm{Aa}$ \\
\hline & 2 & $4,5 \mathrm{Aa}$ & $3,2 \mathrm{Ba}$ & $4,5 \mathrm{ABa}$ \\
\hline & 3 & $2,7 \mathrm{Aa}$ & $4,5 \mathrm{Aa}$ & $3,5 \mathrm{ABa}$ \\
\hline & 4 & $4,5 \mathrm{Aa}$ & 4,0 Aab & $2,7 \mathrm{Bb}$ \\
\hline & CV (\%) & & 25,2 & \\
\hline \multirow{5}{*}{$\begin{array}{l}\text { Produção de Grãos Verdes } \\
\left.\text { (g.planta }{ }^{-1}\right)\end{array}$} & 1 & $2,7 \mathrm{Aa}$ & $4,7 \mathrm{Aa}$ & $3,1 \mathrm{Aa}$ \\
\hline & 2 & $3,0 \mathrm{Aa}$ & $3,2 \mathrm{Aa}$ & 4,3 Aa \\
\hline & 3 & $2,8 \mathrm{Aa}$ & 4,3 $\mathrm{Aa}$ & $2,9 \mathrm{Aa}$ \\
\hline & 4 & 4,9 Аa & $4,7 \mathrm{Aa}$ & $2,4 \mathrm{Aa}$ \\
\hline & $\mathrm{CV}(\%)$ & & 19,1 & \\
\hline \multirow{3}{*}{$\begin{array}{l}\text { Rendimento de Grãos Secos } \\
\qquad\left(\mathrm{kg} \cdot \mathrm{ha}^{-1}\right)\end{array}$} & 3 & $112 \mathrm{Ab}$ & $253 \mathrm{Aa}$ & $179 \mathrm{Aab}$ \\
\hline & 4 & $175 \mathrm{Ab}$ & $328 \mathrm{Aa}$ & $177 \mathrm{Ab}$ \\
\hline & CV (\%) & & 21,7 & \\
\hline
\end{tabular}

Letras maiúsculas: comparações em cada coluna; letras minúsculas: comparações em cada linha (teste de Tukey, p $\leq 0,05$ ).

Ao final do ciclo, também não foram detectadas diferenças estatisticamente significativas entre lotes, dentro de cada ambiente, quanto ao estande final, com exceção para o lote 2 armazenado em laboratório. Houve decréscimo médio de 1 planta/m linear, em relação ao estande inicial, mesmo quando se consideraram os lotes mais vigorosos (Tabela 4), fato considerado normal em ensaios de campo.

A produção de grãos verdes por planta, para a cv. Telefone Alta não foi afetada por possíveis efeitos do vigor (Tabela 4), enquanto efeito estatisticamente significativo de lotes sobre 
o rendimento $\left(\mathrm{kg} \cdot \mathrm{ha} \mathrm{a}^{-1}\right)$ de grãos verdes se manifestou apenas em plantas originadas de sementes do lote 4 armazenado em laboratório (AL). Deve ser destacado que a vantagem do rendimento de grãos verdes em plantas correspondentes ao lote 4 armazenado em laboratório foi associada à superioridade do estande inicial, embora tenham sido considerados apenas os valores numéricos, pois foi estatisticamente significativa apenas em relação às plantas do lote 2 .

Tabela 5. Cultivar Telefone Alta: altura, massa de matéria seca e área foliar de plantas originadas de sementes armazenadas em laboratório (AL), câmara fria e seca (CFS) e ambiente controlado (AC), aos 15 e aos 43 dias após a emergência de plântulas.

\begin{tabular}{|c|c|c|c|c|c|c|c|}
\hline \multirow{3}{*}{ Parâmetros } & \multirow{3}{*}{ Lotes } & \multicolumn{6}{|c|}{ Dias após a semeadura } \\
\hline & & \multicolumn{3}{|c|}{15 dias } & \multicolumn{3}{|c|}{43 dias } \\
\hline & & $\mathrm{AL}$ & CFS & $\mathrm{AC}$ & $\mathrm{AL}$ & CFS & $\mathrm{AC}$ \\
\hline \multirow{5}{*}{ Altura de Plantas (cm.planta ${ }^{-1}$ ) } & 1 & $10,2 \mathrm{Aa}$ & $11,8 \mathrm{Aa}$ & $9,4 \mathrm{Aa}$ & $51,8 \mathrm{Aa}$ & $54,3 \mathrm{Aa}$ & $43,2 \mathrm{Aa}$ \\
\hline & 2 & $9,2 \mathrm{Aa}$ & $11,5 \mathrm{Aa}$ & $10,5 \mathrm{Aa}$ & $48,6 \mathrm{Aa}$ & $51,8 \mathrm{Aa}$ & $44,5 \mathrm{Aa}$ \\
\hline & 3 & $11,3 \mathrm{Aa}$ & $10,6 \mathrm{Aa}$ & $11,0 \mathrm{Aa}$ & $50,3 \mathrm{Aa}$ & $44,1 \mathrm{Aa}$ & $51,7 \mathrm{Aa}$ \\
\hline & 4 & $12,2 \mathrm{Aa}$ & $12,5 \mathrm{Aa}$ & 9,9 Аa & 49,6 Аа & $55,1 \mathrm{Aa}$ & $41,7 \mathrm{Aa}$ \\
\hline & CV $(\%)$ & & 18,7 & & & 18,8 & \\
\hline \multirow{5}{*}{ Matéria Seca (g) } & 1 & $0,13 \mathrm{Aa}$ & $0,18 \mathrm{Aa}$ & $0,11 \mathrm{Aa}$ & $1,56 \mathrm{Ab}$ & $1,84 \mathrm{Aa}$ & $1,28 \mathrm{Aa}$ \\
\hline & 2 & $0,14 \mathrm{Aa}$ & $0,16 \mathrm{Aa}$ & $0,12 \mathrm{Aa}$ & $1,40 \mathrm{Aa}$ & $2,27 \mathrm{Aa}$ & $1,49 \mathrm{Aa}$ \\
\hline & 3 & $0,14 \mathrm{Aa}$ & 0,16 Аа & 0,13 aа & $1,54 \mathrm{Aa}$ & $1,69 \mathrm{Aa}$ & $1,50 \mathrm{Aa}$ \\
\hline & 4 & $0,16 \mathrm{Aa}$ & $0,14 \mathrm{Aa}$ & $0,15 \mathrm{Aa}$ & $1,19 \mathrm{Aa}$ & $1,67 \mathrm{Aa}$ & $1,77 \mathrm{Aa}$ \\
\hline & CV (\%) & & 19,7 & & & 26,3 & \\
\hline \multirow{5}{*}{ Área Foliar $\left(\mathrm{cm}^{2}\right)$} & 1 & $35,5 \mathrm{Aab}$ & $43,5 \mathrm{Aa}$ & $34,7 \mathrm{Ab}$ & $240 \mathrm{Ab}$ & $347 \mathrm{Aa}$ & $220 \mathrm{Ab}$ \\
\hline & 2 & $45,7 \mathrm{Aa}$ & 48,2 Аа & $25,7 \mathrm{Ab}$ & $226 \mathrm{Aa}$ & $271 \mathrm{ABa}$ & $262 \mathrm{Aa}$ \\
\hline & 3 & $33,0 \mathrm{Aa}$ & $35,2 \mathrm{Aa}$ & $33,7 \mathrm{Aa}$ & $226 \mathrm{Aa}$ & $232 \mathrm{Ba}$ & $276 \mathrm{Aa}$ \\
\hline & 4 & $35,2 \mathrm{Aa}$ & $36,5 \mathrm{Aa}$ & $37,5 \mathrm{Aa}$ & $203 \mathrm{Aa}$ & $297 \mathrm{ABa}$ & $277 \mathrm{Aa}$ \\
\hline & CV $(\%)$ & & 24,3 & & & 24,7 & \\
\hline
\end{tabular}

Letras maiúsculas: comparações em cada coluna; letras minúsculas: comparações em cada linha (teste de Tukey, p $\leq 0,05$ ).

Por outro lado, o rendimento de grãos secos também não foi diferente entre lotes, indicando que as variações do vigor não foram suficientes para afetar significativamente a produção final dessa cultivar, mesmo quando ocorreram diferenças no estande. No entanto, não podem ser ignoradas as diferenças numéricas, não detectadas pela análise estatística, revelando tendências para obtenção de rendimentos superiores de grãos verdes para as plantas provenientes do lote 4, armazenado em laboratório (AL), e dos lotes 1 e 4 armazenados em câmara fria e seca (CFS), ou seja, geralmente associadas a diferenças no estande. TeKrony e Egli (1991) destacaram que a produção de grãos não está estreitamente associada ao desenvolvimento vegetativo das plantas, desde que este ultrapasse um nível mínimo para alcançar o potencial produtivo compatível com a cultivar. Assim, mesmo sementes de lotes de menor vigor provavelmente garantiram o impulso inicial para que as plantas atingissem um nível mínimo de desenvolvimento, fato evidenciado quando foi considerado o rendimento de grãos secos (Tabela 4).

A associação direta entre o desempenho de plantas e os estandes inicial e final, geralmente inferior para os lotes mantidos em laboratório e em ambiente controlado, são coincidentes com as observações de Ellis (1992), Hampton (2002) e Marcos Filho (2005), indicando a possibilidade da manifestação de efeitos indiretos do vigor sobre a produtividade, quando há diferenças significativas no estande. Também não foram verificados efeitos de compensação ao desenvolvimento de plantas com maior espaço disponível, pois a produção individual não foi afetada, mesmo sob diferenças de estande.

Paralelamente, a porcentagem de emergência de plântulas da cultivar Itapuã 600 variou entre os lotes, principalmente para os mantidos em laboratório e em ambiente controlado, com destaque para os lotes 5 e 8 , enquanto os lotes 6 e 7 apresentaram redução significativa, confirmando os resultados obtidos nos testes de vigor (Tabelas 3 e 6). 
Tabela 6. Cultivar Itapuã 600: emergência de plântulas em campo, número inicial e final de plantas/m linear, número de vagens/planta, produção de sementes verdes/planta e rendimento de sementes verdes e secas (kg/ha) de plantas originadas de sementes armazenadas em laboratório (AL), câmara fria e seca (CFS) e ambiente artificial (AC).

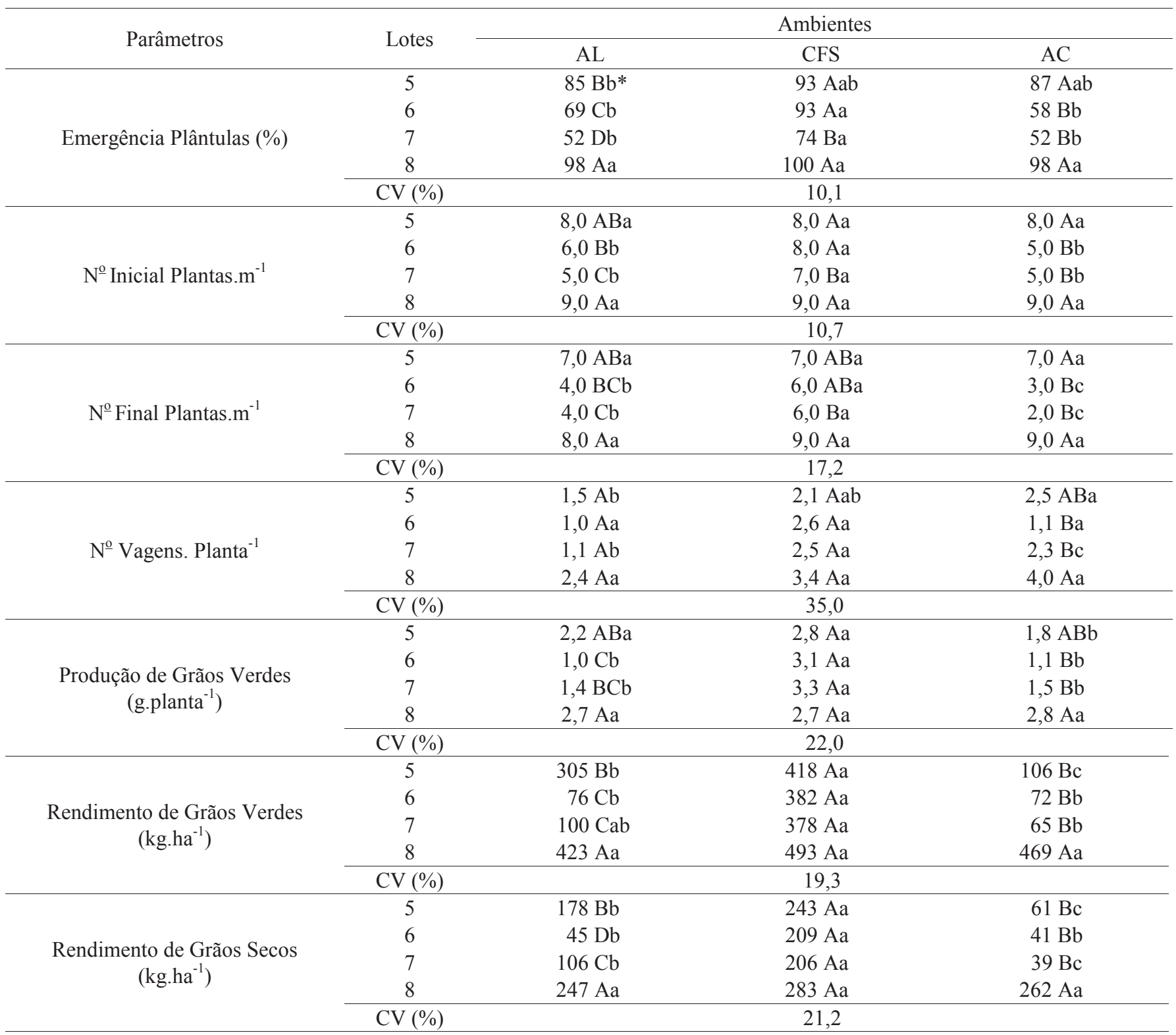

Letras maiúsculas: comparações em cada coluna; letras minúsculas: comparações em cada linha (teste de Tukey, p $\leq 0,05$ ).

Essas tendências se mantiveram quanto aos estandes inicial e final, detectando-se diferenças entre lotes e entre ambientes; novamente, os estandes planejados foram alcançados apenas pelos lotes mais vigorosos, o mesmo ocorrendo para os decréscimos do número final de plantas em relação ao inicial, que foram mais intensos em lotes com menor potencial fisiológico, com predominância de decréscimo de 2,0 plantas $/ \mathrm{m}$ linear entre os estandes inicial e final.

De um modo geral, não foram constatadas variações consistentes entre lotes quanto à altura das plantas aos 15 dias após a semeadura (Tabela 7); aos 43 dias, as plantas provenientes do lote 7 apresentaram menor desenvolvimento. Essa tendência à inferioridade dessas plantas, acompanhadas pelas originadas do lote 6 (dependendo do ambiente de armazenamento) também foi observada nas determinações da massa de matéria seca e área foliar, confirmando existência de relação entre o vigor das sementes e o desenvolvimento inicial das plantas. 
Tabela 7. Cultivar Itapuã 600: altura, massa de matéria seca e área foliar de plantas originadas de sementes armazenadas em laboratório (AL), câmara fria e seca (CFS) e ambiente controlado (AC), aos 15 e aos 43 dias após a emergência de plântulas.

\begin{tabular}{|c|c|c|c|c|c|c|c|}
\hline \multirow{3}{*}{ Parâmetros } & \multirow{3}{*}{ Lotes } & \multicolumn{6}{|c|}{ Dias após a semeadura } \\
\hline & & \multicolumn{3}{|c|}{15 dias } & \multicolumn{3}{|c|}{43 dias } \\
\hline & & $\mathrm{AL}$ & CFS & $\mathrm{AC}$ & $\mathrm{AL}$ & CFS & $\mathrm{AC}$ \\
\hline \multirow{5}{*}{$\begin{array}{l}\text { Altura de Plantas } \\
\left(\mathrm{cm} \text {.plântula }{ }^{-1}\right)\end{array}$} & 5 & $8,2 \mathrm{Aa}$ & $8,7 \mathrm{Aa}$ & $8,6 \mathrm{ABa}$ & $33,4 \mathrm{Aa}$ & $36,0 \mathrm{ABa}$ & $25,0 \mathrm{ABb}$ \\
\hline & 6 & 9,9 Aa & $8,5 \mathrm{Aab}$ & 7,7 ABb & $31,0 \mathrm{Aa}$ & $29,3 \mathrm{Bca}$ & $27,3 \mathrm{ABa}$ \\
\hline & 7 & $9,5 \mathrm{Aa}$ & $7,7 \mathrm{Ab}$ & $6,1 \mathrm{Bc}$ & $27,6 \mathrm{Ba}$ & $24,0 \mathrm{Ca}$ & $23,5 \mathrm{Ba}$ \\
\hline & 8 & $8,8 \mathrm{Aa}$ & $9,0 \mathrm{Aa}$ & $10,3 \mathrm{Aa}$ & $35,8 \mathrm{Aa}$ & $40,1 \mathrm{Aa}$ & $34,8 \mathrm{Aa}$ \\
\hline & CV (\%) & & 16,8 & & & 17,5 & \\
\hline \multirow{5}{*}{ Matéria Seca (g) } & 5 & $0,18 \mathrm{Aa}$ & $0,16 \mathrm{ABa}$ & $0,16 \mathrm{Aa}$ & $1,4 \mathrm{Aa}$ & $1,3 \mathrm{Aa}$ & $1,3 \mathrm{Aa}$ \\
\hline & 6 & $0,15 \mathrm{ABa}$ & $0,13 \mathrm{Ba}$ & $0,15 \mathrm{Aa}$ & $1,5 \mathrm{Aa}$ & $1,3 \mathrm{Aa}$ & $1,0 \mathrm{Ab}$ \\
\hline & 7 & $0,12 \mathrm{Ba}$ & $0,11 \mathrm{Ba}$ & $0,12 \mathrm{ABa}$ & $1,0 \mathrm{Ba}$ & $1,0 \mathrm{Aa}$ & $0,6 \mathrm{Bb}$ \\
\hline & 8 & $0,14 \mathrm{ABab}$ & $0,19 \mathrm{Aa}$ & $0,10 \mathrm{Bb}$ & $1,0 \mathrm{Bb}$ & $1,5 \mathrm{Aa}$ & $1,0 \mathrm{Ab}$ \\
\hline & CV (\%) & & 29,1 & & & 30,6 & \\
\hline \multirow{5}{*}{ Área Foliar $\left(\mathrm{cm}^{2}\right)$} & 5 & $40,7 \mathrm{Aa}$ & $35,5 \mathrm{ABa}$ & $41,5 \mathrm{Aa}$ & $300 \mathrm{Aa}$ & $215 \mathrm{ABab}$ & $162 \mathrm{ABb}$ \\
\hline & 6 & $35,7 \mathrm{ABa}$ & $30,7 \mathrm{Ba}$ & $30,5 \mathrm{ABa}$ & $191 \mathrm{Bc}$ & $192 \mathrm{ABa}$ & $153 \mathrm{ABa}$ \\
\hline & 7 & $26,0 \mathrm{Ba}$ & $24,7 \mathrm{Ba}$ & $25,5 \mathrm{Ba}$ & $150 \mathrm{Ca}$ & $170 \mathrm{Ba}$ & $121 \mathrm{Ba}$ \\
\hline & 8 & $36,2 \mathrm{ABb}$ & $47,0 \mathrm{Aa}$ & $20,7 \mathrm{Bc}$ & $217 \mathrm{BCa}$ & $259 \mathrm{Aa}$ & $245 \mathrm{Aa}$ \\
\hline & CV (\%) & & 21,4 & & & 27,2 & \\
\hline
\end{tabular}

Letras maiúsculas: comparações em cada coluna; letras minúsculas: comparações em cada linha (teste de Tukey, p $\leq 0,05$ ).

As condições climáticas foram favoráveis ao desenvolvimento das plantas, embora tenha ocorrido excesso de chuvas na fase final de maturação (Tabela 1). Assim, as diferenças entre o desempenho de plantas podem ser atribuídas à variação mais ampla no vigor dos lotes de sementes de 'Itapuã 600', em relação à verificada para os lotes de 'Telefone Alta'. Foram, também, observadas diferenças na produção de grãos verdes/planta e de grãos verdes e de grãos secos por área, exceto para os lotes armazenados em câmara fria e seca (Tabela 6). Em geral, esses resultados acompanharam as variações do estande inicial e do estande final; em alguns casos, a produção não diferiu mesmo quando o estande foi afetado, como se verificou na comparação do desempenho dos lotes armazenados em câmara fria e seca. Os resultados desta pesquisa confirmaram, portanto, que os possíveis decréscimos no rendimento são associados à redução do estande, independentemente do hábito de crescimento da cultivar.

Há informações disponíveis na literatura, ressaltando que populações homogêneas ou não, constituídas por sementes de alto vigor geralmente proporcionam produção significativamente superior à das formadas por sementes de baixo ou de menor vigor (Kolchinski et al., 2005; Mondo, 2009; Schuch et al., 2009; Scheeren et al., 2010). No entanto, a constituição de populações homogêneas é muito pouco provável, em termos práticos, pois, independentemente da espécie produtora de grãos, os lotes de sementes normalmente são compostos por indivíduos com variação gradativa do nível de deterioração, ou seja, há desde indivíduos com vigor muito baixo até os altamente vigorosos. Consequentemente, os efeitos do vigor sobre o estabelecimento do estande são predominantes em relação à possível influência sobre a continuidade do desenvolvimento vegetativo e estádios reprodutivos das plantas produtoras de grãos, que mostra associação mais profunda com as relações genótipo/ambiente.

\section{Conclusões}

O vigor das sementes de ervilha influencia a emergência de plântulas e o estabelecimento do estande em campo, especialmente em lotes pouco vigorosos.

$\mathrm{O}$ vigor das sementes de ervilha afeta negativamente o desenvolvimento das plantas e a produção final, quando há redução acentuada do estande; a extensão desses efeitos é proporcional à intensidade dessa redução.

\section{Agradecimentos}

Ao Conselho Nacional de Desenvolvimento Científico 
e Tecnológico (CNPq), pela concessão de bolsas de estudo e de recursos para a condução desta pesquisa.

\section{Referências}

ABDALLA, F.H.; ROBERTS, E.H. The effect of seed storage conditions on the growth and yield of barley, broad beans and peas. Annals of Botany, v.33, p.169-184, 1969.

BRASIL. Ministério da Agricultura, Pecuária e Abastecimento. Regras para análise de sementes. Ministério da Agricultura, Pecuária e Abastecimento. Secretaria de Defesa Agropecuária. Brasília, DF: MAPA/ACS, 2009. 395p. http://www.agricultura.gov.br/arq_editor/file/laborat $\% c 3 \%$ b3rio/ sementes/regras\%20para\%20analise $\% 20 \mathrm{de} \% 20$ sementes.pdf

CALIARI, M.F.; MARCOS FILHO, J. Comparação entre métodos para avaliação da qualidade fisiológica de sementes de ervilha. Revista Brasileira de Sementes, v.12, p.52-73, 1990. http://www.abrates.org.br/ revista/artigos/1990/v12n3/artigo05.pdf

EDJE, O.T.; BURRIS, J.S. Effects of soybean seed vigor on field performance. Agronomy Journal, v.63, p.536-538, 1971.

ELLIS, R.H. Seed and seedling vigor in relation of crop growth and yield. Plant Growth and Regulation, v.11, p.249-255, 1992.

GIORDANO, L.B. Cultivo da ervilha. Brasília: EMBRAPA, CNPH, 1997. 19p. (Instruções Técnicas, 1).

HAMPTON, J.G. What is seed quality? Seed Science and Technology, v.30, p.1-10, 2002.

KHAH, E.M.; ROBERTS, E.H.; ELLIS, R.H. Effects on seed ageing on growth and yield of spring wheat at different plant-population densities. Field Crops Research, v.20, p.175-190, 1989.

KIKUTI, A.L.P.; MARCOS FILHO, J. Potencial fisiológico de sementes de couve-flor e desempenho das plantas em campo. Revista Brasileira de Sementes, v.29, p.107-113, 2007. http://www.scielo.br/scielo.php?script=sci arttext\&pid $=\mathrm{s} 0101-31222007000100015 \& \operatorname{lng}=\mathrm{en} \& \mathrm{nrm}=\mathrm{iso} \& \operatorname{lng}=\mathrm{pt}$

KOLCHINSKI, E.M.; SCHUCH, L.O.B.; PESKE, S.T. Vigor de sementes e competição intra-específica em soja. Ciência Rural, v.35, p.1248-1256, 2005. http://www.scielo.br/scielo.php?script=sci_abstract\&pid=S0103$84782005000600004 \& \operatorname{lng}=$ en $\&$ nrm $=$ iso \& tlng $=$ pt

KOLCHINSKI, E.M.; SCHUCH, L.O.B.; PESKE, S.T. Crescimento inicial de soja em função do vigor de sementes. Revista Brasileira de Agrociência, v.12, p.163-166, 2006.

KOTOWSKI, F. Temperature relations to germination of vegetable seed. Proceedings of the American Society for Horticultural Science, v.23, p.176-184, 1962.

LARSEN, S.U.; POVSEN, F.V.; ERIKSEN, E.N.; PEDERSEN, H.C. The influence of seed vigour on field performance and the evaluation of the applicability of the controlled deterioration vigour test in oil seed rape and pea. Seed Science and Technology, v.26, p.627-641, 1998.

MAKASHEVA, R.K. The pea. Rotterdam: A.A. Balkema, 1984. 267p.

MARCOS FILHO, J. Fisiologia de sementes de plantas cultivadas. Piracicaba: FEALQ, 2005. 495p. (Biblioteca de Ciências Agrárias Luiz de Queiroz, 12).

MARCOS FILHO, J.; KIKUTI, A.L.P. Vigor de sementes de rabanete e desempenho de plantas em campo. Revista Brasileira de Sementes, v.28, p.4451, 2006. http://www.scielo.br/scielo.php?script=sci_arttext\&pid=s0101$31222006000300007 \& \operatorname{lng}=$ en\&nrm=iso\&tlng=pt

MIELEZRSKI, F.; SCHUCH, L.O.B.; PESKE, S.T.; PANOZZO, L.E.; PESKE, F.B.; CARVALHO, R.R. Desempenho individual e de populações de plantas de arroz híbrido em função da qualidade fisiológica das sementes. Revista Brasileira de Sementes, v.30, p.86-94, 2008. http://www.scielo.br/ scielo.php?script $=$ sci_arttext\&pid $=$ s0101-31222008000300012\&lng=en\& nrm=iso\&tlng $=\mathrm{pt}$

MELO, P.T.B.S.; SCHUCH, L.O.B.; ASSIS, F.N.; CONCENÇO, G. Comportamento individual de plantas originadas de sementes com diferentes níveis de qualidade fisiológica em populações de arroz irrigado. Revista Brasileira de Sementes, v.28, p.84-94, 2006. http://www.scielo. br/scielo.php?script=sci_abstract\&pid=s0101-31222006000200011\&lng $=$ en $\&$ nrm $=$ iso $\&$ tlng $=$ pt

MONDO, V.H.V. Vigor de sementes e desempenho de plantas na cultura do milho. 2009. 89p.Tese (Doutorado em Fitotecnia) - Escola Superior de Agricultura “Luiz de Queiroz”, Universidade de São Paulo, Piracicaba, 2009.

NAKAGAWA, J. Testes de vigor baseados no desempenho das plântulas. In: KRZYZANOWSKI, F.C.; VIEIRA, R.D.; FRANÇA-NETO, J.B. Vigor de sementes: conceitos e testes. Londrina: ABRATES, 1999. p.2.1-2.24.

NASCIMENTO, W.M.; CICERO, S.M. Qualidade de sementes de ervilha tratadas com fungicidas. I. Qualidade sanitária. Revista Brasileira de Sementes, v.13, p.5-12, 1991a.

NASCIMENTO, W.M.; CICERO, S.M. Qualidade de sementes de ervilha tratadas com fungicidas. I. Qualidade fisiológica. Revista Brasileira de Sementes, v.13, p.13-19, 1991 b.

NASCIMENTO, W.M.; FREITAS, R.A.; GOMES, E.M.L.; SOARES, A.S. Metodologia para o teste de envelhecimento acelerado em sementes de ervilha. Horticultura Brasileira, v.25, p.205-209, 2007. http://www.scielo.br/scielo.php?script $=$ sci_abstract\&pid=s0102$05362007000200015 \& \operatorname{lng}=\mathrm{en} \& \mathrm{nrm}=\mathrm{iso} \& \operatorname{tng}=\mathrm{pt}$

RODO, A.B.; MARCOS FILHO, J. Onion seed vigor in relation to plant growth and yield. Horticultura Brasileira, v.21, p.220-226, 2003. http://www.scielo.br/scielo.php?script=sci_abstract\&pid=S010205362003000200020\&lng=en\&nrm=iso\&tlng=pt

SCHEEREN, B.R.; PESKE, S.T.; SCHUCH, L.O.B.; BARROS, A.C.S.A. Qualidade fisiológica e produtividade de sementes de soja. Revista Brasileira de Sementes, v.32, p.35-41, 2010. http://www.scielo. 
br/scielo.php?script=sci_arttext\&pid=S0101-31222010000300004\&lng $=$ en\&nrm=iso\&tlng $=\mathrm{pt}$

SCHUCH, L.O.B.; KOLCHINSKI, E.M.; FINATTO, J.A. Qualidade fisiológica e desempenho de plantas isoladas em soja. Revista Brasileira de Sementes, v.31,p.144-149, 2009. http://www.scielo.br/scielo.php?script=sci abstract\&pid=S0101-31222009000100016\&lng=en\&nrm=iso\&tlng=pt

SCHUCH, L.O.B.; NEDEL, J.L.; ASSIS, F.N.; MAIA, M.S. Crescimento em laboratório de plântulas de aveia preta (Avena strigosa Schreb.) em função do vigor das sementes. Revista Brasileira de Sementes, v.21, p.229-234, 1999.

SUN, W.Q. Methods for the study of water relations under desiccation stress. Black, M.; Pritchard, H.W. (Ed.). Desiccation and survival in plants: drying without dying. Wallingford, CABI Publishing. p.48-83, 2002.

TEKRONY, D.M.; EGLI, D.B. Relationship of seed vigor to crop yield: a review. Crop Science, v.31, p.816-822, 1991.

VANZOLINI, S.; CARVALHO, N.M. Efeito do vigor de sementes de soja sobre o seu desempenho em campo. Revista Brasileira de Sementes, v.24, p.33-41, 2002. http://www.scielo.br/scielo.php?script=sci_abstract\&pid=s0101$31222002000100006 \& \operatorname{lng}=$ en\&nrm=iso\&tlng $=$ pt
VIEIRA, R.D.; KRZYZANOWSKI, F.C. Teste de condutividade elétrica. In: KRZYZANOWSKI, F.C.; VIEIRA, R.D.; FRANÇA-NETO, J.B. (Ed.). Vigor de sementes: conceitos e testes. Londrina: ABRATES, 1999. p.1-26.

WUTKE, E.B.; AMBROSANO, E.J.; BULISANI, E.A.; CASTRO, J.L.; GALLO, P.B.; PEREIRA, J.C.V.N.A.; SORDI, G.; BORTOLETTO, N. Espaçamento e população de plantas para a cultura da ervilha de grãos em diferentes regiões paulistas. Ciência e Cultura, Rio de Janeiro, v.43, n.7, p.22, jul. 1991. Suplemento. Apresentado na REUNIÃOANUALDA SOCIEDADE BRASILEIRA PARA O PROGRESSO DA CIÊNCIA, 18., 1991.

ZECCHINELLI, R. The influence of seed quality on crop productivity. In: FAO, Proceedings of the Second World Seed conference - Treponding to the challenges of a changing world: the role of new plant varieties and high quality seed in agriculture. Roma, p.150-158, 2009. 